\title{
Checklijst voor het opsporen van cognitieve en emotionele gevolgen van een beroerte (CLCE-24)
}

Citation for published version (APA):

Rasquin, S. M. C., van Heugten, C. M., Winkens, I., Beusmans, G., \& Verhey, F. R. J. (2006). Checklijst voor het opsporen van cognitieve en emotionele gevolgen van een beroerte (CLCE-24). Tijdschrift voor Gerontologie en Geriatrie, 37(3), 121-126. https://doi.org/10.1007/BF03074778

Document status and date:

Published: 01/01/2006

DOI:

10.1007/BF03074778

Document Version:

Publisher's PDF, also known as Version of record

Document license:

Taverne

Please check the document version of this publication:

- A submitted manuscript is the version of the article upon submission and before peer-review. There can be important differences between the submitted version and the official published version of record.

People interested in the research are advised to contact the author for the final version of the publication, or visit the DOI to the publisher's website.

- The final author version and the galley proof are versions of the publication after peer review.

- The final published version features the final layout of the paper including the volume, issue and page numbers.

Link to publication

\footnotetext{
General rights rights.

- You may freely distribute the URL identifying the publication in the public portal. please follow below link for the End User Agreement:

www.umlib.nl/taverne-license

Take down policy

If you believe that this document breaches copyright please contact us at:

repository@maastrichtuniversity.nl

providing details and we will investigate your claim.
}

Copyright and moral rights for the publications made accessible in the public portal are retained by the authors and/or other copyright owners and it is a condition of accessing publications that users recognise and abide by the legal requirements associated with these

- Users may download and print one copy of any publication from the public portal for the purpose of private study or research.

- You may not further distribute the material or use it for any profit-making activity or commercial gain

If the publication is distributed under the terms of Article $25 \mathrm{fa}$ of the Dutch Copyright Act, indicated by the "Taverne" license above, 


\title{
CheckLijst voor het opsporen van cognitieve en emotionele gevolgen na een beroerte (CLCE-24)
}

\author{
S.M.C. Rasquin • C.M. van Heugten • I. Winkens • \\ G. Beusmans • F.R.J. Verhey
}

Summary : Checklist for the detection of cognitive and emotional consequences after stroke (CLCE-24) Background and purpose. Cognitive and emotional problems are common after stroke and screening is essential. In this paper a new screening instrument is presented and its usability is investigated.

Methods. A group of stroke patients $(\mathrm{N}=69)$ were interviewed using the new instrument, the CLCE-24, six months post stroke. Moreover extensive neuropsychological testing was conducted (including MMSE/ CAMCOG).

Results. Patients, relatives and assessors (a psychologist) were positive about its use. The interview with the CLCE-24 took 11.1 minutes on average (5-35 minutes). Eighty percent of the patients had complaints; $73 \%$ had cognitive problems, while $51 \%$ had emotional problems. Patients with at least one complaint on the CLCE-24 scored lower on the MMSE $(\mathrm{t}=2.5 ; \mathrm{p}=0.01)$ and the CAMCOG $(\mathrm{t}=2.5 ; \mathrm{p}=0.02)$ compared to patients without complaints.

Conclusions. The CLCE-24 can be applied by professionals in primary care for identification of cognitive and emotional complaints after stroke. Further research and implementation in clinical practice and the stroke service is recommended.

Samenvatting Achtergrond en doel: Eerstelijns zorgverleners geven aan dat ondersteuning nodig is voor het onderkennen en signaleren van cognitieve en emotionele stoornissen na een beroerte. Deze studie beschrijft een nieuw signaleringsinstrument, de CheckLijst voor

S.M.C. Rasquin ( $\square)$

iRv, Kenniscentrum voor Revalidatie en Handicap,

HoensbroekAfdeling Neuropsychologie en Psychiatrie,

Universiteit Maastricht
Cognitieve en Emotionele problemen na een beroerte (CLCE-24).

Methode: $\mathrm{Bij}$ een groep patiënten $(\mathrm{N}=69)$ werd 6 maanden na de beroerte voorafgaand aan het uitgebreid neuropsychologisch onderzoek (waaronder de MMSE en CAMCOG) de CLCE-24 afgenomen.

Resultaten: De CLCE-24 werd positief ontvangen door zowel de patiënt, de naaste als de interviewer (psycholoog). De gemiddelde afnameduur was 11.1 minuten (5-35 minuten). Tachtig procent van de patiënten rapporteerde klachten; $73 \%$ cognitieve klachten en 51\% emotionele klachten. Patiënten met ten minste één cognitieve klacht scoorden lager op de MMSE $(\mathrm{t}=2.52 ; \mathrm{p}=0.01)$ en de CAMCOG $(\mathrm{t}=2.45 ; \mathrm{p}=0.02)$ dan patiënten zonder klachten.

Conclusie: De CLCE-24 is een bruikbaar instrument om cognitieve en emotionele klachten na een beroerte op te sporen, waarna verwijzing naar bijvoorbeeld een neuropsycholoog en/of revalidatiearts kan plaatsvinden. Verder onderzoek moet o.a. gericht zijn op betrouwbaarheid tussen beoordelaars en op implementatie in de zorgketen.

Keywords checklijst · cognitieve stoornissen - emotionele stoornissen $\cdot$ cva $\cdot$ beroerte

\section{Inleiding}

Jaarlijks krijgen in Nederland zo'n 30.000 mensen een CVA ofwel beroerte. Een beroerte kan vergaande gevolgen hebben, zowel op fysiek als psychisch vlak. ${ }^{1}$ Het zijn met name de cognitieve en emotionele gevolgen die op lange termijn een belemmering vormen in het dagelijks leven. ${ }^{2,3}$ Werkhervatting en participatie in de 
maatschappij verlopen bij veel patiënten moeizaam. Subtiele klachten blijven vaak onopgemerkt. Personen met dementie of een depressie als gevolg van een beroerte worden door een klinisch geoefend oog snel herkend. Bij veel patiënten komen echter minder duidelijke subjectieve klachten naar voren. Het betreft klachten zoals 'het gaat allemaal te snel', 'het kost zoveel energie', of 'ik ben snel moe'. Deze klachten kunnen duiden op onderliggende cognitieve of emotionele problemen, die de patiënt moeilijk kan benoemen. Hierdoor zullen bij een routineonderzoek door bijvoorbeeld de huisarts, dat doorgaans na een beroerte plaatsvindt, de onderliggende cognitieve of emotionele problemen niet opgemerkt worden. Huisartsen hebben moeite om tijdens een anamnese cognitieve en emotionele klachten te herkennen en na te vragen. ${ }^{4-6}$ Op steeds meer plaatsen in Nederland wordt de zorg rond een beroerte georganiseerd in zogenaamde CVA-zorgketens. Hierbij doorloopt de getroffene de volledige keten van zorg die nodig is rondom een beroerte. In een van de laatste stadia is ook de thuiszorg betrokken bij de zorg. Er wordt verwacht dat de patiënt vooral in de thuissituatie cognitieve of emotionele gevolgen rapporteert omdat dit het moment is dat de patiënt met de beperkingen wordt geconfronteerd. Omdat een thuiszorgcoördinator en een huisarts de sleutelfiguren zijn in deze fase, is het belangrijk dat zij een instrument hebben waarmee ze deze cognitieve of emotionele gevolgen kunnen navragen. De bestaande screeningsinstrumenten zijn niet toereikend voor dit doel, omdat ze vooral gericht zijn op dementie-screening en daardoor te weinig sensitief zijn en emotioneel functioneren volledig buiten beschouwing laten. ${ }^{7,8}$ Bovendien zijn in een eerste verkennend gesprek met de patiënt de meeste vragenlijsten te specifiek dan wel te uitgebreid. In dit artikel presenteren we daarom een nieuw signaleringsinstrument (CheckLijst voor Cognitieve en Emotionele problemen na een beroerte: CLCE-24) dat is ontworpen om zorgverleners in de eerste lijn te ondersteunen bij het herkennen en signaleren van cognitieve en emotionele gevolgen van een beroerte.

Doel van dit artikel is aspecten van de bruikbaarheid en validiteit van het nieuw ontwikkelde instrument te presenteren.

\section{Patiënten en Methode}

Patiënten zijn deelnemers aan het CODAS onderzoek (COgnitive Disorders After Stroke). ${ }^{3,9-15}$ Inclusiecriteria voor de huidige studie waren: eerste supratentoriële beroerte, ouder dan 40 jaar, geen andere neurologische of psychiatrische stoornissen, een MMSE score hoger dan vijftien, goede beheersing van de Nederlandse taal en op zes maanden na de beroerte thuis wonend. Voor het laatste criterium was gekozen omdat de meeste mensen zes maanden na de beroerte weer thuis zijn, alwaar de omvang van de cognitieve en emotionele beperkingen duidelijk wordt en de zorgverleners in de eerste lijn hiermee geconfronteerd worden.

Testmateriaal: De CLCE-24 werd ontwikkeld op basis van bestaande instrumenten, literatuuronderzoek en twee multidisciplinaire expertmeetings. Aan deze expertmeetings namen onder andere leden van patiëntverenigingen, een huisarts, een zenuwarts, wetenschappelijk onderzoeker, neuroloog, revalidatiearts en een psycholoog deel. De volgende eisen werden aan het instrument gesteld: multi-dimensioneel op het gebied van cognitieve en emotionele gevolgen van een beroerte, af te nemen door niet-psychologen, gericht op cognitieve en emotionele gevolgen van de beroerte (niet op stoornissen) en de lijst moet kort en eenvoudig in gebruik zijn. Bovendien moet de uitkomstmaat kwalitatief van aard zijn, dat wil zeggen dat er geen oordeel wordt gegeven in de vorm van een afkappunt voor aantal klachten. Doel van het instrument is niet om op basis van een afkappunt door te verwijzen. Het instrument dient niet als diagnosticum, maar als ondersteuning van een klinisch interview voor het signaleren van cognitieve en emotionele gevolgen van een beroerte. Als de patiënt aangeeft een klacht te hebben kan dit aanleiding zijn om hierover door te vragen. Het verhaal (of de patiënt de klacht al dan niet heeft, in welke mate en in welke situaties) is van belang. Mocht de hulpverlener op basis van dit verhaal het gevoel hebben dat er sprake is van cognitieve of emotionele problematiek dan is doorverwijzing naar bijvoorbeeld een neuropsycholoog of revalidatiearts gewenst.

De CLCE-24 bestaat uit 22 gestandaardiseerde items: vijftien over cognitieve klachten en zeven over emotionele klachten. De laatste twee items zijn blanco en dienen om nog niet genoemde klachten te kunnen rapporteren. Bij elk item kan gescoord worden wie (patiënt, diens naaste, interviewer) de klacht rapporteert. Bij afwezigheid van een klacht wordt ' 0 ' gescoord, bij aanwezigheid een ' 1 '. Op basis van de literatuurgegevens en de resultaten van de expertmeetings werd een eerste versie gemaakt, die vervolgens werd beoordeeld door de experts. De eerste versie werd twee maal aangepast alvorens de conceptversie werd gebruikt in de voorliggende studie. $\mathrm{Na}$ afronding van de studie werd op basis van de expertmeeting de definitieve versie ontwikkeld (zie appendix). In de huidige versie is de mogelijkheid opgenomen om aan te geven hoeveel hinder de klacht met zich meebrengt. Dit wordt niet extra gescoord, maar dient als ondersteuning voor eventuele doorverwijzing. Als een patiënt een klacht rapporteert, maar hiervan geen hinder ondervindt, is behandeling mogelijk overbodig. Een 
aantal items (inzicht, decorumverlies, sociale aspecten) zijn in de huidige versie komen te vervallen wegens te weinig respons bij zowel de patiënt, naaste als interviewer. In de handleiding wordt elk item toegelicht inclusief voorbeeldvragen. Bovendien staat in de handleiding ook beschreven hoe de items gescoord moeten worden (bijvoorbeeld wie aangeeft dat het probleem hinderlijk is). De handleiding geeft ook instructies over eventuele doorverwijzing. De handleiding samen met het signaleringsinstrument is gratis verkrijgbaar via de Info-Bali van het iRv (www.irv.nl).

Om na te gaan hoe de CLCE-24 zich verhoudt ten opzichte van bestaande screeningsinstrumenten die het cognitief functioneren meten, zijn als referentie-instrumenten de Mini Mental State Examination (MMSE) en de CAMCOG gebruikt. ${ }^{16,17}$

Procedure: Als onderdeel van de CODAS studie kregen patiënten op een maand (baseline), zes maanden en twaalf maanden na de beroerte een cognitieve screening. Voordat de cognitieve screening van CODAS zes maanden na de beroerte werd afgenomen, werd aan de patiënten deelname gevraagd voor dit extra onderzoek. De CLCE-24 werd afgenomen voorafgaand aan de cognitieve screening. $\mathrm{Na}$ afname werd de ervaring met de CLCE-24 via een standaardvraag aan zowel de patiënt, de eventuele aanwezige naaste als ook aan de interviewer (een psycholoog) gevraagd. Voor deze studie werd slechts gebruik gemaakt van de gegevens van de patiënt zelf en niet van de naaste. Dit werd gedaan omdat tijdens het onderzoek niet standaard een naaste aanwezig was, waardoor een selectiebias zou kunnen optreden en bovendien rapporteerde de interviewer geen andere klachten dan de patiënt deed. Zes maanden na afname van de CLCE-24 werd de cognitieve screening herhaald.

Statistiek: Beschrijvende statistiek werd gebruikt om algemene kenmerken van de CLCE-24 te bepalen. Voor de toetsende statistiek werden de gegevens van de emotionele items buiten beschouwing gelaten. Dit is gedaan omdat in het CODAS onderzoek de Symptom Checklist $\left(\right.$ SCL-90) ${ }^{18}$ werd gebruikt als maat voor emotionele klachten, echter gezien de scheve verhouding van het aantal items op de SCL-90 (90) ten opzichte van de CLCE-24 (7 emotionele items) werd besloten om deze lijst niet als referentiemaat te gebruiken.

Met een t-toets werd nagegaan of mensen met één of meer cognitieve klachten anders presteren op cognitieve tests dan mensen zonder klachten. Dit onderscheid is gemaakt op basis van het doel van de lijst: signaleren van cognitieve en emotionele gevolgen van een beroerte. Een enkele klacht kan dusdanig hinderlijk zijn dat doorverwijzing noodzakelijk is.
Tabel 1 Patiëntkenmerken

\begin{tabular}{lr}
\hline & $\mathrm{N}(69)$ \\
\hline Geslacht (man/vrouw) & $37 / 32$ \\
Leeftijd (gemiddeld, SD) & $66,1(12,3)$ \\
Opleiding (laag/midden/hoog) ${ }^{1}$ & $35 / 24 / 10$ \\
Beroerte (bloeding/corticaal/lacunair infarct) & $5 / 43 / 21$ \\
Beroerte (links/rechts/beide/geen afwijkingen op CT) & $12 / 19 / 1 /$ \\
& 37 \\
Test locatie (thuis/ziekenhuis) & $51 / 18$ \\
Test situatie (patiënt/patiënt met naaste) & $48 / 21$ \\
Leefsituatie (met partner/alleen/anders) & $49 / 14 / 6$ \\
\hline${ }^{1}$ Laag: Lager (beroeps)onderwijs; Midden: middelbaar onderwijs; & \\
Hoog: volgend op middelbaar onderwijs &
\end{tabular}

\section{Resultaten}

In totaal werden 69 patiënten geïncludeerd. In tabel 1 zijn de patiëntgegevens weergegeven.

\section{Toepasbaarheid van de CLCE-24}

De gemiddelde afname-duur van de CLCE-24 was 11,1 minuten (SD 4,5; range 5-35;87\% binnen 10 minuten). Bij 23\% van de geïnterviewden was de partner aanwezig, bij $4 \%$ een zoon of dochter en bij $3 \%$ een ander familielid. Omdat de aanwezigheid van een naaste geen vereiste was van de studie, zijn de reacties van de naasten niet verder meegenomen in de analyses. De meeste patiënten stonden positief tegenover de CLCE-24: duidelijke vragen, relevante items, goed dat de vragen gesteld worden, de items zijn realistisch en herkenbaar. Geen enkele patiënt vond de lijst te lang of te persoonlijk. Ook de interviewers gaven aan dat het een bruikbaar, hanteerbaar en zinvol instrument is.

\section{Problemen gescoord met de CLCE-24}

Tachtig procent van de patiënten rapporteerde klachten (ten minste een) op de lijst en $51 \%$ van de patiënten had meer dan één klacht $(73 \%$ cognitieve klachten en $51 \%$ emotionele klachten). Het aantal klachten varieerde van 0 tot 14 (gemiddeld 3,3 voor totaal, 2,3 voor cognitie en 1,0 voor emotionele klachten). Aandacht ( $28 \%$ ), mentale traagheid $(26 \%)$ en geheugen $(26 \%)$ waren de meest gescoorde cognitieve klachten. Angst (29\%) en depressie $(35 \%)$ waren de meest gescoorde emotionele klachten. De klachten die op de laatste twee blanco items het meest werden gerapporteerd waren: snel vermoeid, snel geïrriteerd en/of snel emotioneel (in de nieuwe versie daarom als items opgenomen). 
Vergelijking met andere instrumenten

Patiënten die cognitieve klachten rapporteerden op de CLCE-24 hadden een significante lagere score op de $\operatorname{MMSE}(\mathrm{t}=2,52 ; \mathrm{p}=0,01)$ en op de CAMCOG $(\mathrm{t}=$ $2,45 ; \mathrm{p}=0,02)$ in vergelijking met patiënten zonder cognitieve klachten. De groepen verschilden niet qua leeftijd, opleidingsniveau en MMSE gemeten een maand na de beroerte. Wel rapporteerden vrouwen gemiddeld meer klachten $(4,2)$ op de totale lijst dan mannen $(2,6 ; \mathrm{p}<0,04)$. Ook rapporteerden vrouwen meer emotionele klachten dan mannen (gemiddeld aantal klachten voor mannen: 0,6 en voor vrouwen 1,$5 ; \mathrm{p}<$ $0,01)$.

\section{Beschouwing}

Eerstelijnszorgverleners geven aan dat er behoefte is aan ondersteuning bij herkenning van cognitieve en emotionele problematiek na een beroerte. Met de CLCE-24 wordt tegemoet gekomen aan deze wens. De CLCE-24

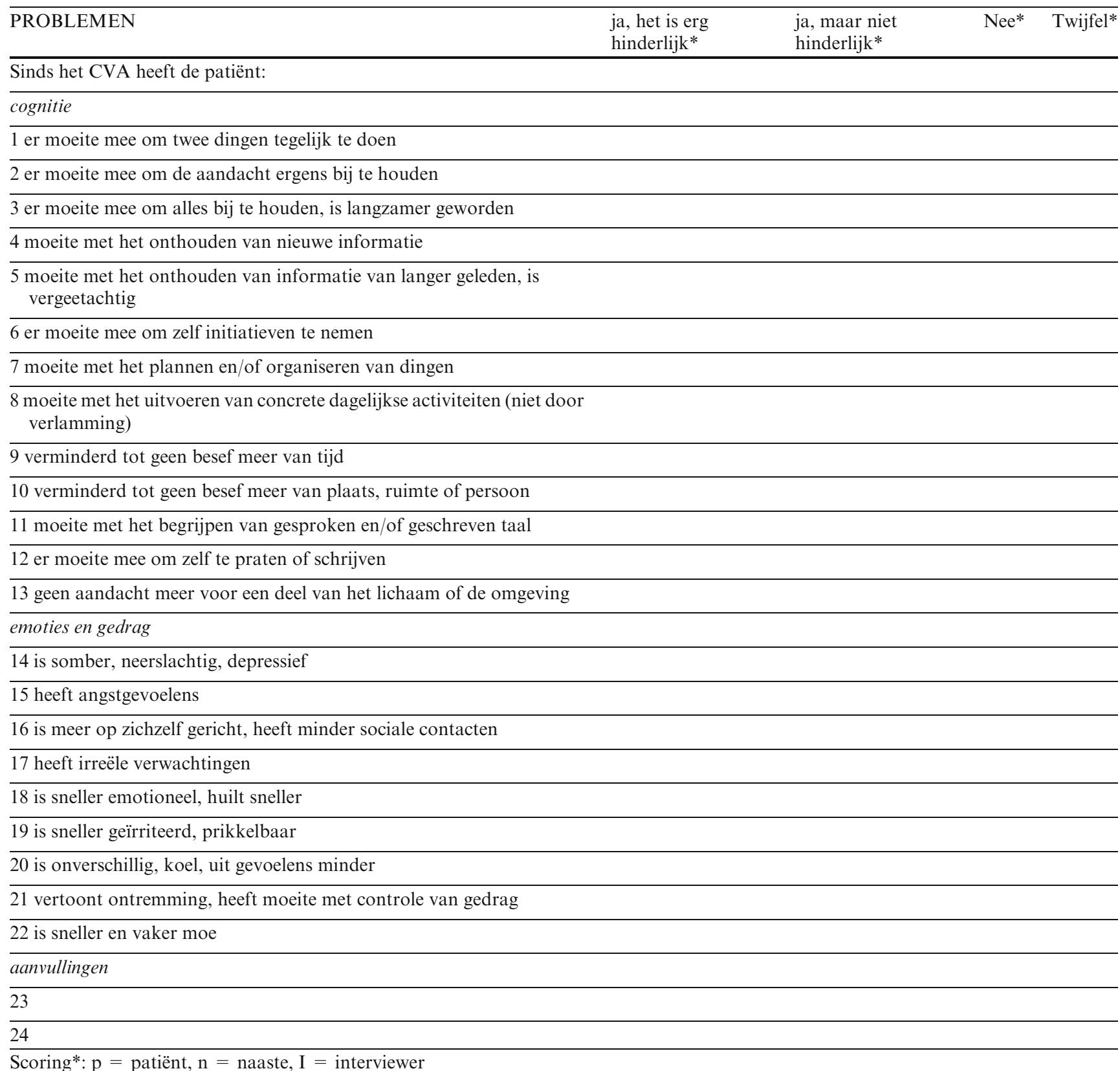


is een bruikbaar instrument in de dagelijkse klinische praktijk. De patiënten en naasten gaven overwegend positieve reacties, evenals de interviewers.

Het instrument heeft slechts een signalerende rol, voor het diagnosticeren van neuropsychologische stoornissen is uitgebreid testonderzoek nodig. Het is wenselijk dat bij een hoge mate van hinder de patiënt wordt doorverwezen naar een neuropsycholoog en/of revalidatiearts. Aldaar kan dan beslist worden om een uitgebreid neuropsychologsich onderzoek te doen, psychoeducatie te geven of over te gaan op behandeling van de problemen in de vorm van cognitieve revalidatie. Dit kan leiden tot een stijging van het aantal neuropsychologische onderzoeken. Echter op de lange termijn zullen de kosten voor de gezondheidszorg naar verwachting minder zijn, omdat deze patiënten minder lang met hun beperkingen zullen blijven rondlopen en er mogelijk geen escalatie van problematiek optreedt door vroegtijdige signalering.

In deze studie werd de CLCE-24, indien mogelijk, tegelijk bij de patiënt en diens naaste afgenomen. Patiënt en partner kunnen evenwel soms uiteenlopende antwoorden geven ( $40 \%$ van de partners in dit onderzoek gaf op minstens één item een ander antwoord dan de patiënt) waardoor het is aan te raden om de CLCE-24 bij patiënt en naaste apart af te nemen. ${ }^{2,19-21}$ Bovendien blijkt de naaste betrouwbare informatie te kunnen geven over het cognitief functioneren van de patiënt. ${ }^{22}$ Bij discrepantie moet via een gesprek met zowel de patiënt als de naaste blijken in hoeverre ondersteuning voor de beperkingen gewenst is. De mogelijkheid voor anderen om cognitieve dan wel emotionele problemen aan te geven op het instrument is opgenomen omdat een veel voorkomend gevolg van de beroerte een verminderd inzicht in eigen functioneren is.

In deze studie werden patiënten met zeer slechte cognitieve prestaties uitgesloten van deelname. Waren deze mensen toch geïncludeerd, dan zou het percentage mensen dat een klacht rapporteert wellicht hoger zijn geweest. Een gevolg hiervan kan zijn dat het verschil tussen mensen met en zonder klachten scherper was, waardoor de resultaten robuuster kunnen zijn.

Toekomstig onderzoek moet gericht zijn op de interbeoordelaarsbetrouwbaarheid en op de implementatie van het signaleringinstrument bij eerstelijns zorgverleners in de CVA-zorgketen. Bovendien moeten criteria opgesteld worden waarbij een onderscheid gemaakt wordt tussen mensen waarbij een vervolgonderzoek raadzaam is en mensen waarbij dit onnodig is. Momenteel wordt het signaleringinstrument door hulpverleners in de thuiszorg al op diverse plaatsen gebruikt en zijn er meerdere revalidatiepoli's waarbij het instrument standaard wordt gehanteerd.

\section{Dankbetuiging}

Het artikel werd mede mogelijk gemaakt door financiering van de Adriana van Rinsum Ponssen Stichting en de Nederlandse Hersenstichting.

\section{Appendix 1. Items van de CLCE-24}

\section{Literatuur}

Tatemichi TK, Desmond DW, Stern Y, Paik M, Sano M Bagiella E. Cognitive impairment after stroke: frequency, patterns, and relationship to functional abilities. J Neurol Neurosurg Psychiatry 1994;57(2):202-7.

Hochstenbach J, Mulder T,van Limbeek J, Donders R, Schoonderwaldt H. Cognitive decline following stroke: a comprehensive study of cognitive decline following stroke. J Clin Exp Neuropsychol 1998;20(4):503-17.

Rasquin SMC, Lodder J, Ponds RWHM, Winkens I, Jolles J, Verhey FRJ. Cognitive functioning after stroke: a one-year follow-up study, 2004. 18: p. 138-144.

Loor HI, Groenier KH, Schuling J, Meyboom-de Jong B. Depressiviteit na een cerebrovasculair accident: het oordeel van de huisarts. Huisarts Wet 1999;42:299-302.

Aben I, Verhey FRJ, Beusmans G, Lodder J. Depressie na een CVA: signalering, diagnostiek en behandeling in de huisartsenpraktijk. Huisarts Wet 2003;46(9):487-492.

De Lepeleire JA, Heyrman J, Baro F, Buntinx F, Lasuy C. How do general practitioners diagnose dementia? Fam Pract 1994;11 (2):148-52.

Brodaty H, Clarke J, Ganguli M, Grek A, Jorm A F, Kachaturian $\mathrm{Z}$, Scherr Screening for cognitive impairment in general practice: toward a consensus. Alzheimer Dis Assoc Disord 1998;12 (1):1-13

Nys GM, van Zandvoort MJ, de Kort OL, Jansen, BP, Kappelle LJ, de Haan EH. Restrictions of the Mini-Mental State Examination in acute stroke. Arch Clin Neuropsychol, 2005. 20 (5): 623-9.

Rasquin SMC, Lodder J, Verhey FRJ. Predictors of reversible Mild Cognitive Impairment after stroke: a two year followup study. Journal of Neurological Sciences. 2005. 229-230: 215 .

Rasquin SMC, Lodder J, Verhey FRJ. The effect of different diagnostic criteria on the prevalence and incidence of poststroke dementia. Neuroepidemiology 2005. 24: 189-195.

Rasquin, SMC, et al. Predicitve accuracy of MCI-subtypes for Alzheimer's disease and vascular dementia in subjects with mild cognitive impairment: a 2-year follow-up study. Dement Geriatr Cogn Disord 2004: 19(2-3):113-119.

Rasquin SMC, Verhey FRJ, Lousberg R, Winkens I, Lodder J. Vascular cognitive disorders. Memory, mental speed and cognitive flexibility after stroke. J Neurol Sci 2002;203-204 (C):115-9.

Rasquin SMC, Lodder J, van Oostenbrugge RJ, Lousberg R, Verhey FRJ. Demographic and CT-scan features related to cognitive impairment in the first year after stroke. J Neurol Neurosurg Psychiatry 2005. In press.

Rasquin, SMC, et al. Vascular cognitive disorders. Memory, mental speed and cognitive flexibility after stroke. J Neurol Sci, 2002. 203-204(C): 115-9.

Rasquin SMC, Verhey FRJ, Lodder J. The influence of psychiatric symptoms on cognitive performance after stroke. Cerebrovasc Dis, 2005. 19(5): 309-16. 
Folstein MF, Folstein SE, McHugh PR. "Mini-mental state". A practical method for grading the cognitive state of patients for the clinician. J Psychiatr Res 1975;12(3):189-98.

Verhey FRJ, Huppert FA, Korten ECCM, Houx, PJ, de Vugt ME, van Lang $\mathrm{N}$, et al. Cross-sectional comparison of the Cambridge Cognitive Examnination -revised: The CAMCOG-R. Age and Aging 2003;32:1-7

Arrindell WA and Ettema JHM. Symptom Checklist [Handleiding bij een multidimensionele psychopathologie-indicator]. 2003, Lisse: Swets \& Zeitlinger B.V.

Visser-Keizer AC, Meyboom-de Jong B, Deelman BG, Berg IJ, Gerritsen MJ. Subjective changes in emotion, cognition and behaviour after stroke: factors affecting the perception of patients and partners. J Clin Exp Neuropsychol 2002;24 (8): 1032-45

Hochstenbach, J., et al., Long-term outcome after stroke: a disability-orientated approach. Int J Rehabil Res, 1996. 19(3): p. 189-200.

Hochstenbach J, Donders R, Mulder T, Van Limbeek J, Schoonderwaldt $\mathrm{H}$. Long-term outcome after stroke: a disabilityorientated approach. Int J Rehabil Res 1996;19(3):189-200.

Starr JM, Nicolson C, Anderson K, Dennis MS, Deary IJ. Correlates of informant-rated cognitive decline after stroke. Cerebrovasc Dis 2000;10(3):214-20. 